\title{
AS PESQUISAS EM EDUCAÇÃO EM CIÊNCIAS NA INTERFACE COM A EDUCAÇÃO INDIGENA: a abordagem qualitativa na evidência dos dados
}

THE RESEARCHES IN SCIENCE EDUCATION IN THE INTERFACE WITH INDIGENOUS EDUCATION: the qualitative approach in the evidence of the data

Lúcia Helena Soares de Oliveira ${ }^{1}$ Licurgo Peixoto de Brito ${ }^{2}$ Josefina Barrera Kalhil ${ }^{3}$

\section{RESUMO}

Neste trabalho faz-se uma discussão sobre os paradigmas metodológicos utilizados nos últimos dez anos nas pesquisas em Educação em Ciências e Educação Indígena. Abordamos o levantamento realizado nas bases de dados dos Portais da Capes, BDTD e Google Acadêmico. O estudo faz parte como base teórica de uma pesquisa que está em andamento no âmbito do Programa de Pós-Graduação em Educação em Ciências e Matemática- REAMEC, pela Universidade Federal de Mato Grosso do Sul, polo-UEA. Este estudo tem caráter bibliográfico e se ampara na investigação por meio de levantamentos realizados em artigos, Teses, Dissertações e trabalhos de especialistas que abordam a temática em questão. Assim, os estudos refletem que a abordagem qualitativa permite a compreensão detalhada dos significados e das características situacionais dos sujeitos envolvidos, preocupa-se com uma realidade que não pode ser quantificado e nem reduzido à operacionalização de variáveis, enfatizando que a finalidade da pesquisa cientifica não está centrada tão somente na exposição de um relatório ou descrição dos dados, mas no relato do desenvolvimento interpretativo dos dados obtidos.

Palavras chave: Educação Indígena; Ensino de Ciências; Paradigmas metodológicos.

\begin{abstract}
In this paper we discuss the methodological paradigms used in the last ten years in research in Education in Science and Indigenous Education. We approached the survey carried out in the databases of the Portals of Capes, BDTD and Google Scholar. The study is part of the theoretical basis of a research that is underway within the scope of

\footnotetext{
${ }^{1}$ Doutoranda do Programa de pós-graduação em Educação em Ciências e MatemáticaREAMEC e Professora da Universidade Nilton Lins. oliveiralucia63@ hotmail.com

${ }^{2}$ Doutor em Fisica e Prof ${ }^{\circ}$ Orientador do Programa de pós-graduação em Educação em Ciências e Matemática- REAMEC. Licurgo.brito@gmail.com

${ }^{3}$ Doutora em Ciências Pedagógicas e Professora e Coordenadora do pólo Amazonas do Doutorado em Rede de Educação em Ciências e Matemática- REAMEC. josefinabk@ gmail.com
}

Revista REAMEC, Cuiabá - MT, v. 5, n. 2, jul/dez 2017, ISSN: 2318-6674

Revista do Programa de Doutorado da Rede Amazônica de Educação em Ciências e Matemática http://periodicoscientificos.ufmt.br/ojs/index.php/reamec 


\section{REVISTA REAMEC}

Revista da Rede Amazônica de Educação

em Ciências e Matemática

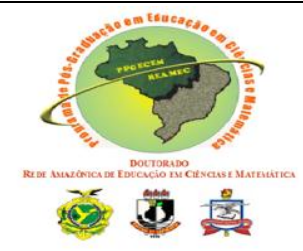

the Post-Graduate Program in Science and Mathematics Education - REAMEC, by the Federal University of Mato Grosso do Sul, umbrella. This study has a bibliographic character and is supported in the research through surveys carried out in articles, Theses, Dissertations and works of specialists that approach the subject in question. Thus, the studies reflect that the qualitative approach allows the detailed understanding of the meanings and the situational characteristics of the subjects involved, is concerned with a reality that can not be quantified or reduced to the operationalization of variables, emphasizing that the purpose of the scientific research does not is centered only on the presentation of a report or description of the data, but on the report of the interpretative development of the data obtained.

Keywords: Indigenous Education; Science teaching; Methodological paradigms

\section{INTRODUÇÃO}

A pesquisa científica exige uma sistemática nas ações desenvolvidas ao longo do processo que sejam efetivamente planejadas com qualidade formal, onde a percepção emancipatória do sujeito comece a se reconstruir a partir da realidade. Diante das inúmeras formas de conhecimento aquele que pesquisa precisa inteirar-se da melhor maneira de conhecer o objeto escolhido, pois os caminhos que se estenderão nessa trajetória podem permitir rupturas, truncamentos nem sempre perceptível no primeiro olhar. Todavia, se o modelo escolhido para esse conhecer oportunizar sustentação para as expectativas esperadas, com certeza, o caminhar será firme e claro diante das problemáticas que porventura surgirem.

Desse modo, muitos métodos tem se apresentado com efetiva sustentação para investigar as ações e relações que permeiam o envolvimento do objeto com seu meio, com prevalência significativa a partir do século XIX da abordagem qualitativa nos estudos relacionados aos fenômenos humanos e sociais. Essa prevalência foi resultante da inquietação dos pesquisadores que se indagavam se um modelo numa perspectiva positivista poderia ser sempre o modelo escolhido para explicar os fenômenos da sociedade.

Neste sentido, buscamos estudar qual paradigma metodológico poderia sustentar uma pesquisa acerca dos saberes tradicionais indígenas Baré para a aprendizagem em Ciências Naturais, visto que, mesmo existindo políticas públicas voltadas para uma

Revista REAMEC, Cuiabá - MT, v. 5, n. 2, jul/dez 2017, ISSN: 2318-6674

Revista do Programa de Doutorado da Rede Amazônica de Educação em Ciências e Matemática http://periodicoscientificos.ufmt.br/ojs/index.php/reamec 


\section{REVISTA REAMEC}

Revista da Rede Amazônica de Educação

em Ciências e Matemática

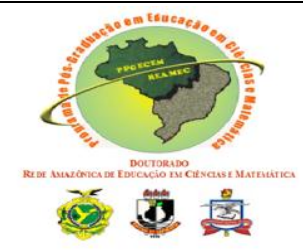

educação indígena, diferenciada, pouco ainda se efetiva como modo de ensinar e aprender os diferentes saberes em consonância com os conteúdos curriculares, principalmente os conteúdos de Ciências Naturais no contexto amazônico.

Assim, no primeiro momento deste trabalho "Um povo a conhecer" são traçados algumas considerações sobre o processo histórico e a Constituição de 1988 e o movimento de Educação Escolar como resultado das conquistas dos movimentos indigenistas.

$\mathrm{Na}$ continuidade, "O conhecimento científico e os paradigmas metodológicos (Quantitativo e Qualitativo)" faz-se uma discussão sobre o desafio em abordar cientificamente um tipo de fato e a opção por um tipo de enfoque que dê conta da área de estudos à qual vai se aplicar. Na parte da sessão "As pesquisas em Educação em ciências na interface com a educação indígena" aborda as pesquisas realizadas nos últimos dez anos no Brasil.

$\mathrm{Na}$ metodologia e análise dos dados aponta-se os achados na pesquisa encontrados em teses, dissertações e artigos dos periódicos da capes, Google acadêmico e BDTD.

O artigo é proveniente de um levantamento bibliográfico, que se põe como base teórica de uma pesquisa ${ }^{4}$ em desenvolvimento no Programa de Pós-Graduação em Educação em Ciências e Matemática (REAMEC) da Universidade Federal de Mato Grosso do Sul, polo/UEA e a investigação feita tomou como referencial de análise os artigos científicos, teses e dissertações publicadas no período de 2007 a 2017, além dos trabalhos de especialistas que abordam a temática em questão.

Para este trabalho, a sustentação do levantamento se baseou na abordagem qualitativo-quantitativo, visto que, o estudo procura encontrar o sentido de um determinado fenômeno e interpretar significados que as pessoas atribuem a ele, retirando um mais rico conjunto de dados envolvidos na pesquisa (CHIZZOTTI, 2006, p. 26).

\footnotetext{
4 A pesquisa referida tem por título "Destaque dos saberes tradicionais indígenas Baré para a aprendizagem em Ciências Naturais" do Programa REAMEC/UEA, em andamento.
}

Revista REAMEC, Cuiabá - MT, v. 5, n. 2, jul/dez 2017, ISSN: 2318-6674

Revista do Programa de Doutorado da Rede Amazônica de Educação em Ciências e Matemática http://periodicoscientificos.ufmt.br/ojs/index.php/reamec 


\section{REVISTA REAMEC}

Revista da Rede Amazônica de Educação

em Ciências e Matemática

Desse modo, entendendo a complexidade do tema discutido neste trabalho, têmse a intenção de nortear concepções introdutórias, na finalidade de suscitar questionamentos e reflexões que possam contribuir para a pesquisa nesta área do conhecimento.

\subsection{Um povo a conhecer}

Reconhecer os povos indígenas como povos tradicionais, implica entender primeiramente quem são esses povos. Segundo uma definição técnica das Nações Unidas de 1986, os povos indígenas são aqueles que com uma continuidade histórica consideram a si mesmos distintos de outros setores da sociedade e decididos a conservar, a desenvolver e a transmitir às gerações futuras sua identidade étnica conforme seus padrões culturais e sistemas jurídicos (LUCIANO, 2006).

Os processos ocorridos ao longo da História brasileira foram decisivos para que os povos indígenas somente a partir da Constituição de 1988 fossem reconhecidos como tais e como detentores de direitos históricos. Constituindo-se assim, como um marco na legitimação dos direitos ao instituir um capítulo exclusivo sobre eles, o Capítulo VIII "Dos Índios".

Na Constituição Federal de 1988 os artigos: 210, 215, 231 e 232 fazem reconhecimento aos índios com relação a sua organização social, costumes, línguas, crenças e tradições, assim como, aos direitos originários sobre as terras que tradicionalmente ocupam, deliberando que compete à União demarcá-las, proteger e fazer respeitar todos os seus bens. Garantindo o direito a Educação Escolar, referente ao ensino Fundamental regular, que seja ministrado em língua portuguesa e nas suas próprias línguas maternas respeitando seus processos próprios de aprendizagem.

Sob o ordenamento contido neste Capítulo, a Constituição de 1988 trouxe uma perspectiva que ultrapassou viés assimilacionista que conduziu a política indigenista brasileira desde seus primórdios, bem como garantiu o direito originário dos povos indígenas sobre suas terras.

Foi por meio do Capítulo VIII "Dos índios" que os povos indígenas passaram a ter direito de serem diferentes da sociedade nacional e de serem reconhecidos como

Revista REAMEC, Cuiabá - MT, v. 5, n. 2, jul/dez 2017, ISSN: 2318-6674

Revista do Programa de Doutorado da Rede Amazônica de Educação em Ciências e Matemática http://periodicoscientificos.ufmt.br/ojs/index.php/reamec 


\section{REVISTA REAMEC}

Revista da Rede Amazônica de Educação

em Ciências e Matemática

povo (BRASIL, 1988). Assim, o pertencimento ao grupo étnico implica a aceitação de valores e traços culturais, uma vez que a cultura "não é algo dado, posto, algo dilapidável também, mas algo constantemente reinventado, recomposto, investido de novos significados" (CHARTIER, 2002).

Nesta perspectiva, a história da educação escolar indígena é modulada pelas nuanças da interação da escola com a diversidade do grupo a que se destina. No limiar do século XXI, as Escolas Indígenas se tornam mais visíveis, tanto pela magnitude numérica, como pelo diferencial que propõem amparadas por um conjunto de leis especificas que destoam da legislação escolar de cunho nacional.

No inicio do século XX a escola para os índios já se constituía em uma preocupação do Estado. $\mathrm{Na}$ atualidade, o tema reaparece forte no panorama da educação escolar, gerando fecundas discussões acerca do ensino diferenciado, em que os próprios interessados estão à frente desse movimento, inaugurando um novo período na história da educação dos povos indígenas e abrindo fendas na marcante homogeneidade das práticas escolares dominantes (RIBEIRO, 2006).

Nesse novo cenário a Educação Indígena acontece em diversos espaços e é gerada naturalmente entre os membros da comunidade. Dessa forma, os povos indígenas têm seus próprios mecanismos de transmissão e de armazenar conhecimentos, levando em conta desde o processo resultante da oralidade no ensino da Língua, como as representações simbólicas presentes nos adereços, grafismos, musicas, literatura, medicina e todo o universo cultural.

Tudo existia antes mesmo da instituição escola ser introduzida nas comunidades, os povos indígenas perpetuam seus conhecimentos e suas maneiras de entender o mundo com seus métodos próprios de ensino, "desenvolveram uma atitude de investigação científica, procurando estabelecer ordenamento no mundo natural [...]" (MAHER, apud GRUPIONI, 2006).

Estabeleceram sua ciência a partir das experiências e conhecimentos adquiridos e passados por gerações e gerações. Cada etnia possui seu processo diferenciado, "quando fazemos menção à "Educação Indígena", estamos nos referindo aos processos educativos tradicionais de cada povo indígena. Aos processos nativos de socialização de suas crianças" (MAHER, p.17, 2006).

Revista REAMEC, Cuiabá - MT, v. 5, n. 2, jul/dez 2017, ISSN: 2318-6674

Revista do Programa de Doutorado da Rede Amazônica de Educação em Ciências e Matemática http://periodicoscientificos.ufmt.br/ojs/index.php/reamec 


\section{REVISTA REAMEC}

Revista da Rede Amazônica de Educação

em Ciências e Matemática

Com base nisso, percebe-se que a Educação Indígena está além do espaço escolar, que possui metodologias tradicionais eficazes, que são traços de culturas que passam por gerações através desses métodos que não estão sistematizados na lógica tradicional da Educação Institucional.

É extremamente importante reconhecer que os povos indígenas mantêm vivas as suas formas de educação tradicional, que podem contribuir na formação de uma política e uma prática educacional adequadas, capazes de atender aos anseios, interesses e necessidades diárias da realidade atual (SILVA, 1999, p.64).

A escola indígena diferenciada colabora com a afirmação étnica, com o reconhecimento e a identificação cultural, numa construção permanente da identidade cultural sólida. A escola que atua juntamente com a comunidade indígena determina a alteridade, pois “a educação indígena não é a mão estendida à espera de uma esmola. É a mão cheia que oferece às nossas sociedades uma alteridade e uma diferença, que nós já perdemos” (MELIÀ, 1999, p. 16).

A função da escola para a comunidade indígena não é simplesmente acadêmica, a verdadeira escola educa em todos os sentidos e permite uma participação intensa da comunidade em suas atividades. Essas comunidades existem em unidade, valorizam o bem comum e prezam por seus integrantes, vivenciando essa maneira de ser dentro na escola.

Nesse movimento, que envolve a educação indígena o conceito de cultura explica o simbólico que se entranha entre os saberes tradicionais e o processo de escolarização formal. De acordo com Geertz (1989, p.14) alguns conceitos antropológicos sustentam que a cultura de um povo pode ser "o modo de vida global de um povo", "uma forma de pensar, sentir e acreditar", " comportamento aprendido" e " uma teia de significados que o próprio homem teceu".

Nessa compreensão, Luciano (2006) afirma que a cultura indígena se manifesta ainda na atualidade expressando seus valores, por meio das solenidades de suas festas, pelo refinamento dos vestuários, na expressão da pintura corporal, na educação dos filhos no cotidiano e na concepção sagrada do cosmo. Essas expressões culturais manifestam a consciência moral, estética, religiosa e social de cada povo.

Revista REAMEC, Cuiabá - MT, v. 5, n. 2, jul/dez 2017, ISSN: 2318-6674

Revista do Programa de Doutorado da Rede Amazônica de Educação em Ciências e Matemática http://periodicoscientificos.ufmt.br/ojs/index.php/reamec 


\section{REVISTA REAMEC}

Revista da Rede Amazônica de Educação

em Ciências e Matemática

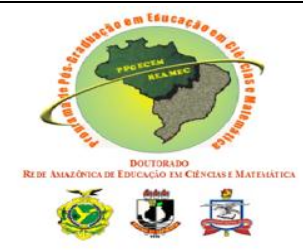

Que o que o homem é pode estar tão envolvido com onde ele está, quem ele é e no que ele acredita, que é inseparável deles. É precisamente o levar em conta tal possibilidade que deu margem ao surgimento do conceito de cultura e ao declínio da perspectiva uniforme do homem (GEERTZ, 1989, p. 47).

A representação do viver do homem indica suas crenças e o seu envolvimento com o meio. Nesse paralelo, entre a cultura e como a represento surge um processo aparentemente igualitário que é a educação. Igualitário não no modo de reprodução, mas sim na ação de como se transmite os diferentes conhecimentos independentes de qual sociedade faz parte.

A comunidade indígena, tanto como povo quanto como aldeia, tem uma racionalidade operante que temos que saber descobrir para que as novas ações pedagógicas possam praticá-la.[...] não há um problema de educação indígena, há sim uma solução indígena ao problema da educação (MELIÀ, 1999, p.16).

A diferença na transmissão do conhecimento entre os indígenas e não indígenas infringe incompreensões que resultam em perdas significativas, pois por mais que a cultura indígena seja objeto de pesquisa em muitos cenários, o conhecimento tradicional tem sido utilizado somente como tripé no campo da pesquisa, mas sem receber o devido valor quando diz respeito ao conhecimento científico. Conhecimento esse muitas vezes elaborado a partir das etapas que o conhecimento tradicional trilhou primeiro.

Relembrando um pouco da História é somente a partir de 1970 que no cenário brasileiro aparece à defesa dos índios pela sua sobrevivência física e cultural. É a partir dessa década que passam a criar e organizar seus movimentos sociais, organizações e associações indígenas com a finalidade de se defenderem das políticas de integração reivindicando o reconhecimento de seus direitos e de suas falas (BERNAL, 2009).

Nesse mesmo vislumbre Silva (2004, p. 67) diz, que os processos educativos para as populações indígenas da Amazônia são recentes, com a educação para a formação de lideranças acontecendo em concomitância com acontecimentos relacionados à afirmação ou reafirmação das diferenças étnicas.

Neste contexto, uma educação pensada pelas lideranças indígenas reforça o pensamento de que esse acesso possibilita a permanência dos estudantes índios nas suas aldeias e com isso a contribuição dessa permanência com o seu povo são profícuos.

Revista REAMEC, Cuiabá - MT, v. 5, n. 2, jul/dez 2017, ISSN: 2318-6674

Revista do Programa de Doutorado da Rede Amazônica de Educação em Ciências e Matemática http://periodicoscientificos.ufmt.br/ojs/index.php/reamec 


\section{REVISTA REAMEC}

Revista da Rede Amazônica de Educação

em Ciências e Matemática

Além do que, a vivência na comunidade mantém viva a cultura diminuindo o impacto que a educação mediada pelo Estado causa no afastamento do indivíduo da comunidade.

Reconhece-se que o enfraquecimento cultural dos povos foi reforçado pela educação das forças dominantes por meio da descaracterização das culturas e tradições dos índios (SILVA, 2004). Isto implica em que a educação indígena sempre existiu e continua sendo instrumento para a sobrevivência e convivência entre as diferentes culturas.

O Ensino Fundamental, nos anos iniciais, foi durante muito tempo a única etapa de ensino ofertada nas escolas indígenas. Sua universalização ainda hoje continua sendo um desafio, com indícios da inadequação das estruturas educacionais e da ineficácia das políticas públicas que visam garantir aos estudantes indígenas o acesso, permanência e conclusão com êxito dessa etapa da Educação Básica.

Diante das rupturas que o processo escolar apresenta, mesmo assim, o território indígena se constitui um espaço que transcende o referencial de território geográfico, pois se faz local de aprendizagens, de vivências, de trocas e de elaborações culturais.

\section{O conhecimento científico e os paradigmas metodológicos (Quantitativo e Qualitativo)}

O conhecimento sempre foi à força motriz para a compreensão dos problemas que a humanidade enfrenta para sua sobrevivência. Desde os tempos antigos o conhecimento foi objeto de busca, explicado por Aristóteles por meio da metafísica onde à admiração causou o despertar. Em Platão pelo Teeteto, o dialogo sobre a natureza do conhecimento num confronto entre verdade e relativismo (OLIVA, 2011). Todavia, a necessidade de conhecer para sobreviver fez o homem transformar o espantoso em formulações de questões e elaborações de conceitos que somente ele poderia elaborar.

Assim, a busca do conhecimento pelo homem não se limitou a só saciar necessidades materiais, mas também responder os questionamentos intelectuais e resolver os problemas que podiam por em risco sua sobrevivência.

Revista REAMEC, Cuiabá - MT, v. 5, n. 2, jul/dez 2017, ISSN: 2318-6674

Revista do Programa de Doutorado da Rede Amazônica de Educação em Ciências e Matemática http://periodicoscientificos.ufmt.br/ojs/index.php/reamec 


\section{REVISTA REAMEC}

Revista da Rede Amazônica de Educação

em Ciências e Matemática

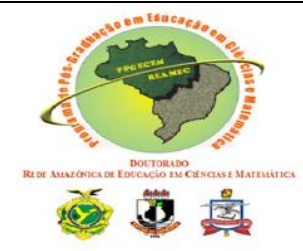

Giambattista Vico (1744/1999 APUD GHEDIN, 2017) em sua tese "A ciência

Nova" diz que só conhecemos o que criamos, ou que participamos de sua criação, por isso a natureza é tão complexa para o homem, pois nesse processo não teve participação ativa. Afirma ainda, que só quando o conhecedor e o autor são a mesma entidade é que o conhecimento se faz possível.

Oliva (2011 apud GHEDIN, 2017) diz que o mundo é composto por várias crenças que ajudam o próprio homem a justificar seu conhecimento e sustentar suas crenças. Entende-se também, que a ciência é a interligação de saberes, como um processo que vai se desenvolvendo conforme o individuo dele se apropria e organiza para seu uso.

Para Freire (1996) o processo de apropriação do novo conhecimento é um percurso libertário do pensamento aprisionado pelo saber do senso comum. Valorizar uma aprendizagem que contextualize a ciência e o senso comum significa experimentar essa libertação.

Nessa compreensão, Bachelard (1996, p. 17) diz que "quando se procuram as condições psicológicas do progresso da ciência, logo se chega à convicção de que é em termos de obstáculos que o problema do conhecimento científico deve ser colocado". Nessa continuidade, Moreira (2002) analisa que desde as conjecturas e refutações de Popper; a resolução de problemas de um paradigma de Kuhn; os programas de pesquisa com núcleo firme de Lakatos; o obstáculo epistemológico de Bachelard e a Teoria dos campos conceituais de Vergnaud sustentam discussões criticas acerca da condução do conhecimento e da apropriação desse conhecimento pelo próprio individuo.

Também, Fourez (1995, p.18-19) diz que a "reflexão filosófica parte de uma experiência muito simples: do fato de que, em uma primeira aproximação, servimo-nos de dois tipos de linguagem para falar do mundo. Linguagem do dia a dia, necessário para a prática e o discurso científico partilhado entre os sujeitos que utilizam esse conhecimento.

Numa afirmação pertinente, Marconi e Lakatos (2011, p.21) fazem uma síntese do conceito de ciência que são apontados como "conhecimentos sistemáticos; conhecimento do real pelas suas causas; estudo de problemas solúveis, mediante

Revista REAMEC, Cuiabá - MT, v. 5, n. 2, jul/dez 2017, ISSN: 2318-6674

Revista do Programa de Doutorado da Rede Amazônica de Educação em Ciências e Matemática http://periodicoscientificos.ufmt.br/ojs/index.php/reamec 


\section{REVISTA REAMEC}

Revista da Rede Amazônica de Educação

em Ciências e Matemática

método científico e conjunto de enunciados lógica e dedutivamente justificados por outros enunciados", dentre outros.

Desta maneira, a preocupação em descobrir e explicar a natureza vem desde os primórdios. O conhecimento mítico voltou sua explicação para o caráter sobrenatural, com verdades impregnadas de forças e potências sobrenaturais. O conhecimento religioso por outro lado, revestiu-se de caráter dogmático transcendental. Por seu lado, o conhecimento filosófico parte para a investigação racional buscando a essência imutável do real na compreensão das leis da natureza (MARCONI e LAKATOS, 2011).

Assim, segundo Sampieri (2006) ao longo da História da ciência foram surgindo diversas correntes de pensamento. Pensamentos estes que se apoiaram no empirismo, no materialismo dialético, no positivismo, na fenomenologia e no estruturalismo. E cada uma dessas correntes apontou rotas de como compreender e interpretar o conhecimento de maneira explicativa.

Para Oliva (2011) o desafio em abordar cientificamente um tipo de fato depende da compreensão certa ou errada do que é vivido. É importante saber, que a opção por um tipo de enfoque depende da área de estudos à qual vai se aplicar. Assim como, determinar o tratamento metodológico que se mostre competente para enfrentar a intrincada problemática respeitando os requisitos básicos de avaliação epistêmica é fator que deve ser priorizado pelo pesquisador.

Nesta perspectiva, a motivação da pesquisa depende dos fatos que chamam a atenção com relação à problemática suscitada e esse processo metodológico exige um percurso bem delineado voltado "à aquisição de conhecimentos com vistas à aplicação numa situação especifica" (GIL, 2010).

Para ilustrar, Sampieri (2006, p.04) aponta duas abordagens (quantitativos e qualitativos) e essas abordagens são paradigmas de pesquisa científica, pois ambos empregam processos cuidadosos, sistemáticos e empíricos em seus esforços para gerar conhecimento e utilizam fases similares e relacionadas entre si, tais como:

a) Llevan a cabo observacion y evaluacion de fenomenos.

b) Establecen suposiciones ideas como consecuencia de la observacion y evaluacion realizadas.

c) Demuestran el grade en que las suposiciones o ideas tienen fundamento.

Revista REAMEC, Cuiabá - MT, v. 5, n. 2, jul/dez 2017, ISSN: 2318-6674

Revista do Programa de Doutorado da Rede Amazônica de Educação em Ciências e Matemática http://periodicoscientificos.ufmt.br/ojs/index.php/reamec 


\section{REVISTA REAMEC}

Revista da Rede Amazônica de Educação

em Ciências e Matemática

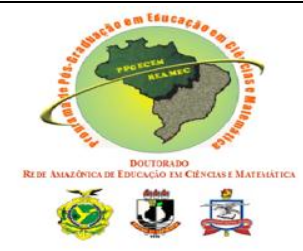

d) Revisan tales suposiciones o ideas sobre la base de las pruebas o del anilisis.

e) Proponen nuevas observaciones y evaluaciones para esclarecer, modificar y fundamentar las suposiciones e ideas; o incluso para generar otras.

Ainda que, as abordagens compartilhem estratégias globais, cada uma tem suas próprias características, por exemplo, o "Enfoque cuantitativo usa la recolección de datos para probar hipotesis, con base en la medicion numerica y el análisis estadístico, para establecer patrones de comportamiento y probar teorias (SAMPIERI, 2006, p.05).

Por outro lado, o "enfoque cualitativo utiliza la recoleccion de datos $\sin$ medicion numérica para descubrir o afinar preguntas de investigacion en el proceso de interpretacion". Assim, o enfoque qualitativo em muitos casos, referido como investigação naturalista, fenomenológica, interpretativa e etnográfica é uma espécie de "guarda-chuva" em que uma variedade de concepções se ampara nele (IDEM, p.8).

Reportando-nos ainda a Sampieri (2006, p. 13), temos a explicação de que amparados por esse enfoque existe uma variedade de concepções e marcos de interpretações que faz parte de uma cultura de ver o mundo. E esses modelos culturais se encontram no centro desse estudo, pois são entidades flexíveis e maleáveis se constituindo marcos de referencia para o ator social e instintos constituindo pelo inconsciente e transmitido pelos outros pela experiência pessoal.

Neste sentido, o caminhar metodológico parte da compreensão que a abordagem qualitativa (CRESWELL, 2010) permite uma melhor aproximação de objetos de estudo próprios do campo educacional, visto a grande complexidade neste contexto.

Assim como, Chizzotti (2006, p. 26) diz que o termo qualitativo implica "[...] uma partilha densa com pessoas, fatos e locais que constituem objetos de pesquisa" para que se possa "extrair desse convívio os significados visíveis e latentes que somente são perceptíveis a uma atenção sensível”. Com este fim, a pesquisa qualitativa procura encontrar o sentido de um determinado fenômeno e interpretar significados que as pessoas atribuem a ele.

Revista REAMEC, Cuiabá - MT, v. 5, n. 2, jul/dez 2017, ISSN: 2318-6674

Revista do Programa de Doutorado da Rede Amazônica de Educação em Ciências e Matemática http://periodicoscientificos.ufmt.br/ojs/index.php/reamec 


\section{REVISTA REAMEC}

Revista da Rede Amazônica de Educação

em Ciências e Matemática

2.1 As pesquisas em Educação em Ciências na interface com a Educação Indígena.

Em consonância com a síntese acima, as pesquisas realizadas nos últimos dez anos em Educação em ciências e matemática na interface com o ensino de ciências naturais e educação indígena, apontam resultados significantes que confirmam que o paradigma qualitativo é oportuno e viável, para as pesquisas voltadas para a área educacional, com envolvimento nos conhecimentos culturais.

Essa premissa está fundamentada nos achados encontrados na pesquisa bibliográfica acerca do tema. Para esse fim, o levantamento bibliográfico se deteve na internet, nos portais da Capes, Google Acadêmico e BDTD (Biblioteca Digital de Teses e Dissertações), visto que, de modo geral esses sites disponibilizam artigos, projetos de pesquisa, relatórios científicos, livros, resenhas, ensaios, dissertações, teses e outros recursos midiáticos.

Para este levantamento, foram considerados somente teses, dissertações e artigos publicados no período de 2007 a 2017, utilizando as categorias delimitadas para a pesquisa como: Educação em Ciências; Educação Científica; Ensino de Ciências e Educação Indígena como termos de busca na base de dados selecionadas.

Inicialmente, considerando as palavras-chave referentes ao tema, as bases de dados apontaram um quantitativo significativo de trabalhos como, por exemplo, Capes (486), BDTD (78) e Google Acadêmico (28) para o período estabelecido.

No entanto, com a leitura sistemática dos resumos e textos completos teve-se um resultado importante, pois o quantitativo de 592 trabalhos apontados no momento inicial da pesquisa criou uma expectativa de que havia muitos estudos com o tema proposto, no entanto, no processo de análise dos trabalhos encontrados, o quantitativo foi reduzido para 68 como mostra a Figura 1.

Dentre os estudos encontrados, as dissertações apresentaram um quantitativo superior aos das teses e artigos, e alguns trabalhos como dissertação e artigo eram similares em bases diferentes, ou então, o mesmo trabalho se repetindo em mais de uma base pesquisada.

Revista REAMEC, Cuiabá - MT, v. 5, n. 2, jul/dez 2017, ISSN: 2318-6674

Revista do Programa de Doutorado da Rede Amazônica de Educação em Ciências e Matemática http://periodicoscientificos.ufmt.br/ojs/index.php/reamec 


\section{REVISTA REAMEC}

Revista da Rede Amazônica de Educação

em Ciências e Matemática
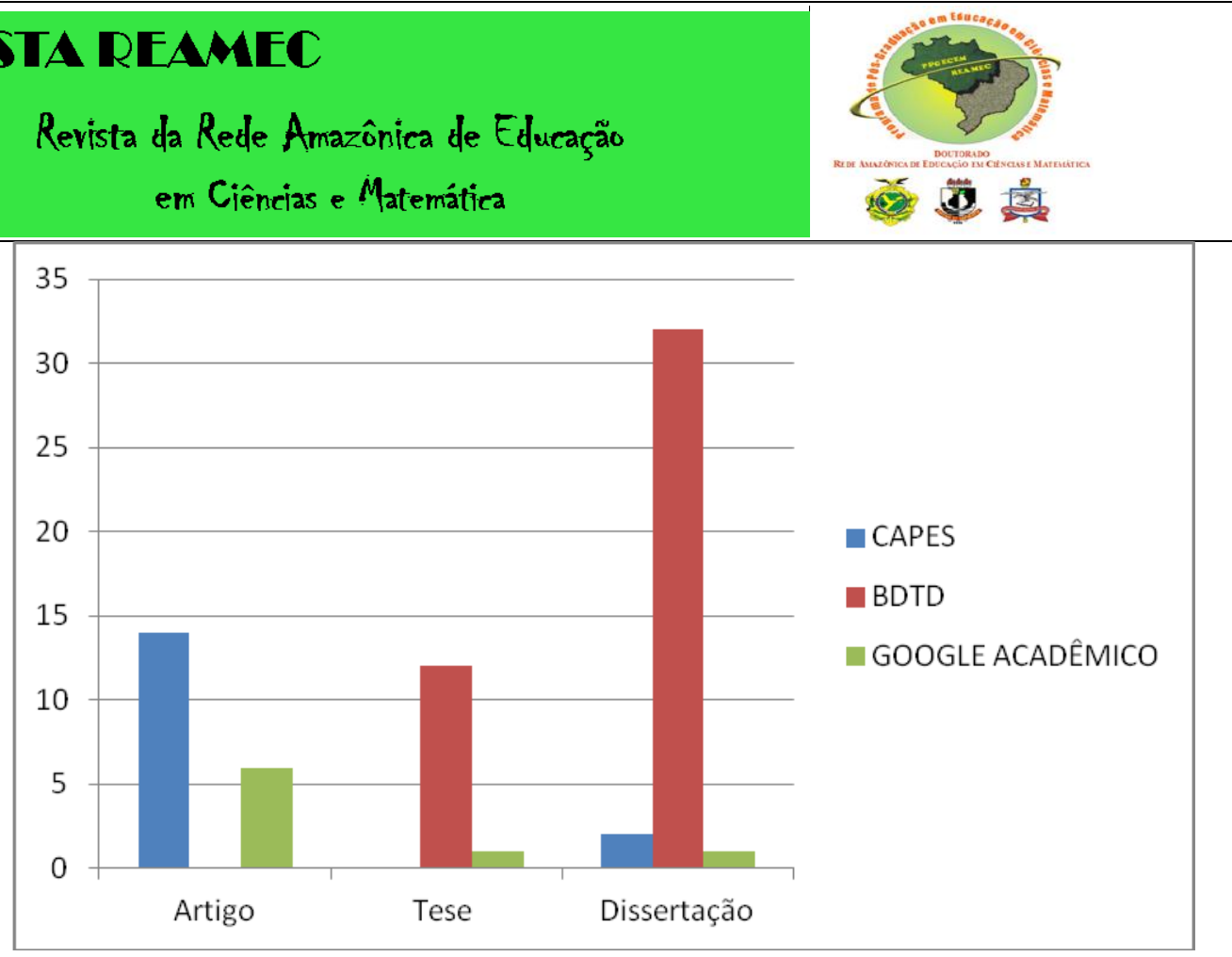

Figura 1- Quantitativo de trabalhos referente ao tema da pesquisa. Fonte: OLIVEIRA/2017

Nesta perspectiva, nos achados podem-se elencar estudos que dão conta do entrelaçamento entre a educação em ciências e os saberes indígenas com pesquisas que apontam a Integração entre a cultura cientifica e cultura artística no ensino de ciências (FLORES, 2016; PEREIRA, 2014; VIEIRA, 2013). A formação de professores em ciências (TREVISAN 2015; SANTOS, 2016; MAIA, 2015; RIBEIRO, 2016) na compreensão das concepções e ações que sustentam o ensino de ciências. $\mathrm{Na}$ interdisciplinaridade com a matemática e a etnociência (PEDROSA, 2015; FERREIRA, 2014; ANTUNES, 2011; OLIVEIRA, 2016) buscando uma mobilização de conhecimentos de maneira critica.

Vale ressaltar, que mesmo com uma representação significativa de trabalhos nessa área de investigação, os estudos acerca dessa temática ainda são escassos, aludindo que há necessidade de se discutir a educação em ciências, assim como a educação indígena de forma que as práticas pedagógicas possam ser socializadas de maneira que contribua com o processo de ensino e aprendizagem vigente nos espaços escolares. O país possui um número representativo de alunos indígenas distribuídos em toda a sua educação básica e essa magnitude numérica precisa ser considerada e valorizada nas suas singularidades.

Revista REAMEC, Cuiabá - MT, v. 5, n. 2, jul/dez 2017, ISSN: 2318-6674

Revista do Programa de Doutorado da Rede Amazônica de Educação em Ciências e Matemática http://periodicoscientificos.ufmt.br/ojs/index.php/reamec 


\section{REVISTA REAMEC \\ Revista da Rede Amazônica de Educação \\ em Ciências e Matemática

\section{MATERIAIS E MÉTODOS}

A metodologia utilizada esteve ancorada nas abordagens qualitativo-quantitativo, visto ser uma investigação que combina as duas abordagens em conjunto, de modo que a força geral de um estudo seja maior do que a da pesquisa qualitativa ou quantitativa isolada (SAMPIERI, 2006, CRESWELL, 2010).

Nesta intencionalidade, objetivou-se conhecer quais os paradigmas metodológicos que tem sustentado as pesquisas em Educação em Ciências na interface da Educação Indígena na última década.

A metodologia foi bibliográfica mediada pela internet nas bases de dados dos portais da Capes, BDTD e Google Acadêmico. Para este levantamento, selecionaram-se somente teses, dissertações e artigos publicados no período de 2007 a 2017.

A busca dos dados nas bases especificadas considerou os aspectos relevantes de cada Base. Na Plataforma de Periódicos Capes o sistema foi de busca avançada, esse sistema dispõe de dois campos para inserção de termos para busca. Esses campos poderiam ser concatenados com um dos operadores: E, OU, NÃO. Para essa finalidade utilizamos o "E" com as seguintes categorias (Educação em Ciências "e" Educação Indígena; Educação Científica "e" Educação Indígena; Ensino de Ciências "e" Educação Indígena) ressaltando, que cada inserção do conjunto de categoria na plataforma foi buscada de maneira separada.

Por outro lado, no portal de busca da Biblioteca Digital Brasileira de Teses e Dissertações (BDTD) os termos de busca foram avançados considerando "and" entre os operadores. A plataforma dispõe da possibilidade de três campos simultâneo de busca: "(Todos os campos: educação em ciências And educação indígena) E (Todos os campos: Educação cientifica AND educação indígena) E (Todos os campos: Ensino de ciências AND educação indígena)" todos os termos foram buscados ao mesmo tempo.

De maneira similar, a busca no Google Acadêmico foi concatenada combinando-se a ocorrência concomitante de um parâmetro ou parâmetros. Isto possibilitou a consulta com as categorias "Educação em ciências OR Educação científica OR Ensino de ciências" AND "Educação Indígena" em uma única ação.

Revista REAMEC, Cuiabá - MT, v. 5, n. 2, jul/dez 2017, ISSN: 2318-6674

Revista do Programa de Doutorado da Rede Amazônica de Educação em Ciências e Matemática http://periodicoscientificos.ufmt.br/ojs/index.php/reamec 


\section{REVISTA REAMEC}

Revista da Rede Amazônica de Educação

em Ciências e Matemática

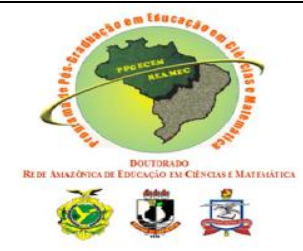

Para análise dos 592 trabalhos encontrados nos buscadores especificados foram considerados as categorias apontadas e o período pesquisado. As leituras iniciais foram dos resumos se alternando ao texto completo diante da necessidade de encontrar o dado pesquisado. No tratamento dos dados as categorias determinaram o quantitativo, pois muitos dos trabalhos estavam concatenados somente pelas palavras-chave, mas não eram referencia para a pesquisa, pois estavam relacionados a outros campos de pesquisa que não era educação.

A análise qualitativa considerou as categorias apresentadas pelos teóricos referentes aos paradigmas metodológicos e a análise quantitativa os recursos que a Microsoft Office Excel oportuniza para as inferências numéricas dos dados (SAMPIERI, 2006, CRESWELL, 2010).

\section{RESULTADOS E DISCUSSÃO}

\subsection{A abordagem Qualitativa na evidência dos dados}

Diante da exposição sistemática elencada acima, os dados analisados se constituíram de substancial valor para a pesquisa realizada. A pesquisa mostra um quantitativo suficiente para uma análise significativa dos trabalhos produzidos nos últimos dez anos, pois dos 68 trabalhos distribuídos entre Artigo, Tese e Dissertação verifica-se que a produção para a Educação em Ciências na interface com a Educação indígena dá caminho para uma mudança na compreensão da necessidade de se pensar os saberes tradicionais indígenas como elemento mediador do conhecimento.

A evidência das pesquisas sendo publicadas por meio de artigo contribui para um cenário animador, pois os saberes tradicionais indígenas transitam no cotidiano da mesma forma que os saberes escolares formais (RIBEIRO, 2006).

É interessante verificar que o tema tem transitado com certa frequência no decorrer dos dez anos como mostra a Figura 2.

Revista REAMEC, Cuiabá - MT, v. 5, n. 2, jul/dez 2017, ISSN: 2318-6674

Revista do Programa de Doutorado da Rede Amazônica de Educação em Ciências e Matemática http://periodicoscientificos.ufmt.br/ojs/index.php/reamec 


\section{REVISTA REAMEC}

Revista da Rede Amazônica de Educação em Ciências e Matemática

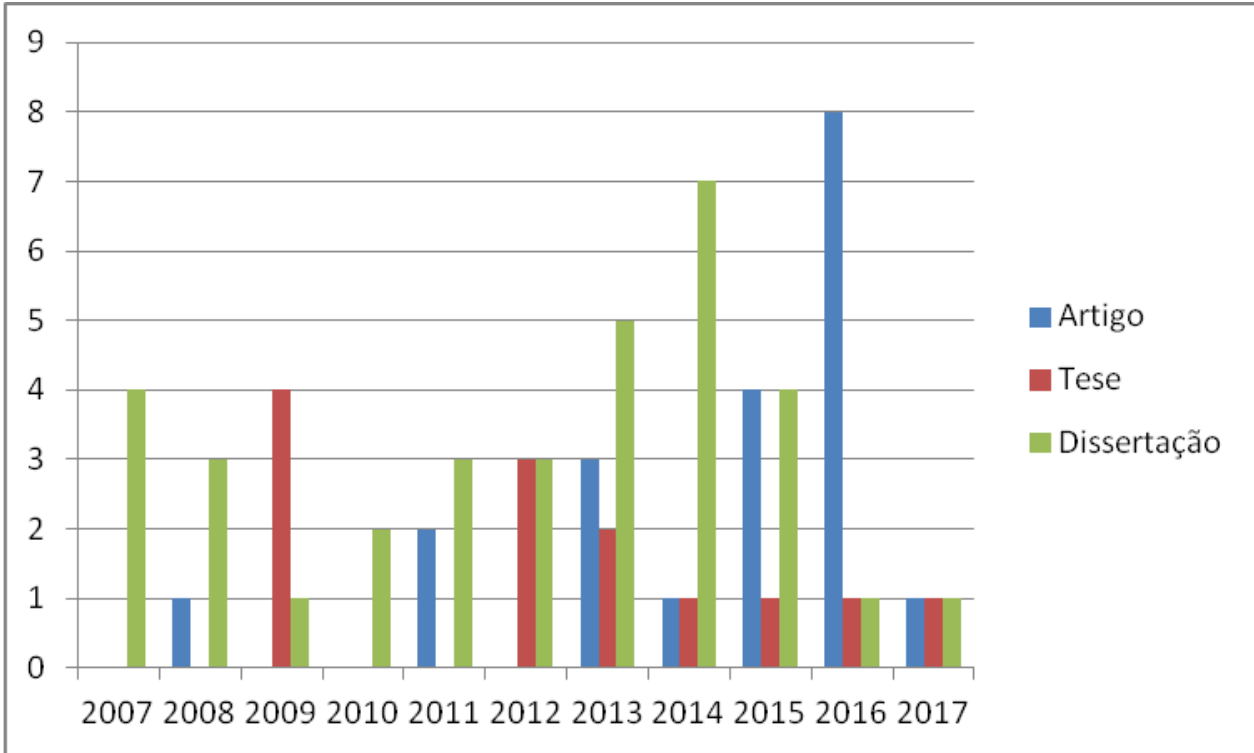

Figura 2- Trabalhos publicados por ano

Fonte: OLIVEIRA/2017

Muito embora, a delimitação da pesquisa tenha considerado os últimos dez anos, no entanto, não se descarta que em anos anteriores, pesquisas possam ser verificadas. Todavia, os resultados apontam que artigos e dissertações apresentam uma regularidade crescente nas bases de dados.

Assim, diante dos achados como mostra a Figura 3, o enfoque que mais prevalece nos estudos pesquisados com relação aos paradigmas metodológicos são os estudos com abordagem qualitativa. Mesmo que, nos trabalhos analisados a descrição apareça como Pesquisa Etnográfica, Pesquisa Narrativa, Pesquisa de Campo e Pesquisaação, contudo, segundo André (2002, p.27) esses "tipos de pesquisa aparecem associados a essa abordagem", mesmo com similaridades e diferenças. Assim como, a descrição da complexidade humana detalhada.

Nesta perspectiva, Marconi e Lakatos (2011, p. 270) afirmam que "o surgimento da pesquisa qualitativa deu-se quando os antropólogos, que estudavam indivíduos, tribos e pequenos grupos ágrafos, perceberam que os dados não podiam se quantificados, mas sim interpretados".

Revista REAMEC, Cuiabá - MT, v. 5, n. 2, jul/dez 2017, ISSN: 2318-6674

Revista do Programa de Doutorado da Rede Amazônica de Educação em Ciências e Matemática http://periodicoscientificos.ufmt.br/ojs/index.php/reamec 


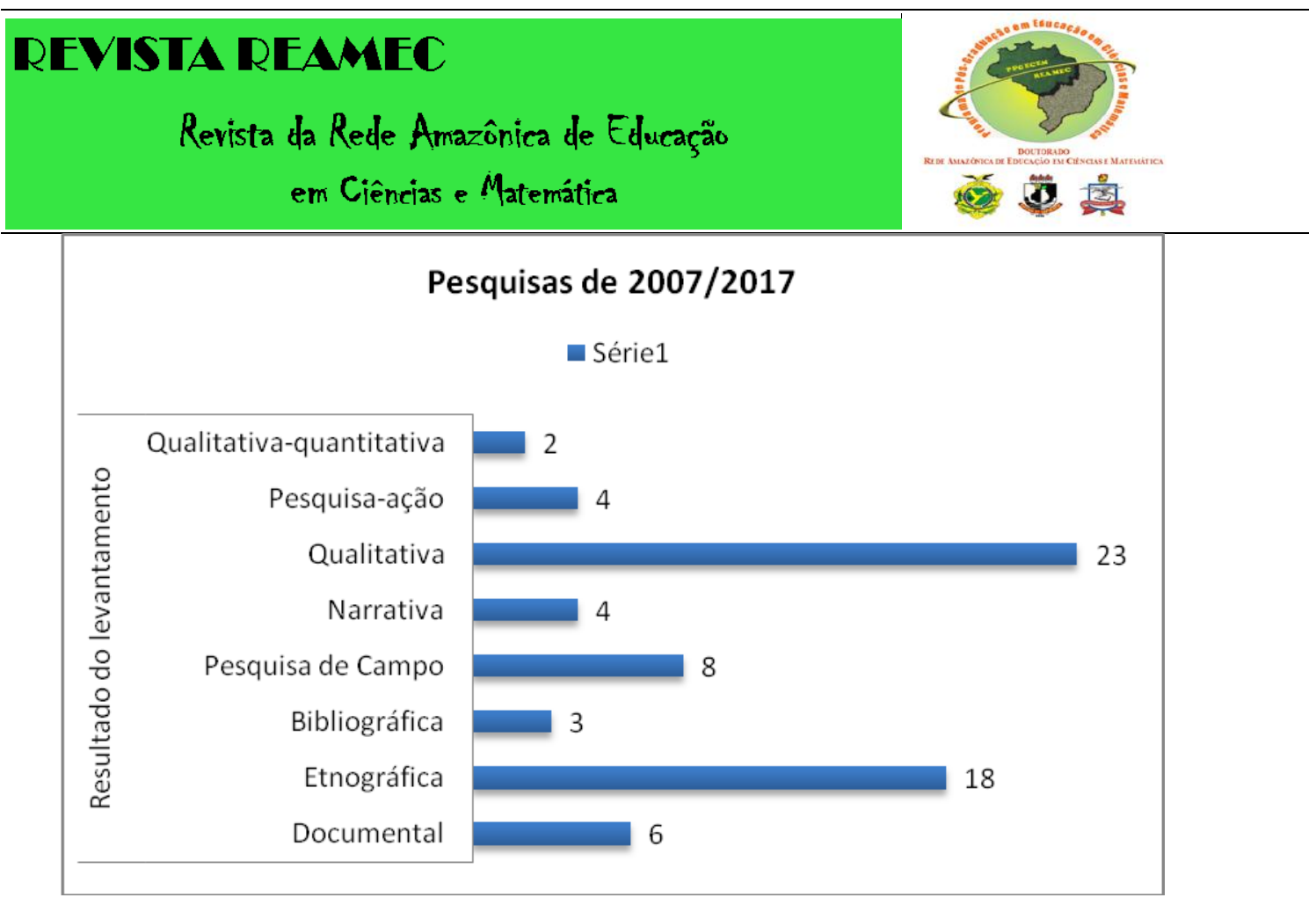

Página | 298

Figura 3- Resultado das evidências metodológicas

Fonte: OLIVEIRA/2017.

$\mathrm{Na}$ análise, verificou-se que a escolha da abordagem qualitativa se deu por conta dos objetivos da pesquisa envolveram o interesse a respeito dos atores sociais e como suas concepções seriam percebidas no cotidiano. Coaduna-se Creswell (2010, p. 28) quando diz que a "pesquisa qualitativa é um meio para explorar e para entender o significado que os indivíduos ou os grupos atribuem a um problema social ou humano". A pesquisa nesse enfoque envolve questões que emergem e a análise parte das particularidades para os temas gerais.

A Figura 3 aponta que a etnografia teve um resultado significativo numericamente, nas descrições os trabalhos estavam envolvidos com a educação em ciências e a cultura étnica. Nessa sustentação, Gil (2010) nos diz, que a pesquisa etnográfica é muito utilizada para a descrição de elementos de uma cultura especifica, assim como, no estudo de organizações e sociedades complexas. É uma estratégia, onde o pesquisador estuda um grupo cultural intacto em um cenário natural durante um período de tempo prolongado, coletando principalmente dados observacionais e de entrevistas. O processo de pesquisa é flexível e se desenvolve, tipicamente, de maneira contextual em resposta às realidades vividas encontradas no ambiente de campo.

Revista REAMEC, Cuiabá - MT, v. 5, n. 2, jul/dez 2017, ISSN: 2318-6674

Revista do Programa de Doutorado da Rede Amazônica de Educação em Ciências e Matemática http://periodicoscientificos.ufmt.br/ojs/index.php/reamec 


\section{REVISTA REAMEC}

Revista da Rede Amazônica de Educação

em Ciências e Matemática

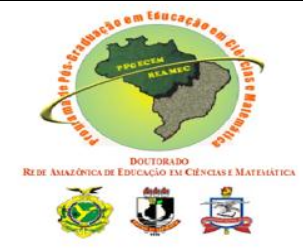

Nesta perspectiva, acolhe-se a visão de Creswell (2010, p. 42) quando diz que a "abordagem qualitativa é uma concepção construtivista, com modelo etnográfico e observação do comportamento". Desse modo, o pesquisador procura então estabelecer o significado de um fenômeno partindo do ponto de vista dos participantes. Isto significa identificar o grupo que compartilha uma cultura e estudar como esse grupo desenvolve padrões de comportamentos no decorrer do tempo.

Neste sentido, os trabalhos analisados afirmam que nos últimos dez anos a abordagem metodológica utilizada nas pesquisas envolvendo a educação em ciência e a educação indígena esteve fundamentada nos pressupostos do paradigma qualitativo.

Muito embora, em alguns dos trabalhos o termo qualitativo não seja utilizado na forma gráfica, contudo, na leitura do texto completo, verificam-se os termos que denunciam a sustentação dessa abordagem, pois as técnicas e os instrumentos para a coleta de dados apontam uma análise não inferencial numérica, pois "o objeto por excelência da pesquisa qualitativa é a ação interpretada, simultaneamente, pelo pesquisador e pelos sujeitos da pesquisa; de onde a importância da linguagem e das conceituações que devem dar conta tanto do objeto "vivido", como do objeto “analisado” (DESLAURIERS e KÉRISIT, 2008, p.131) estão presentes nesses estudos.

\section{CONSIDERAÇÕES}

Esta pesquisa se configurou como base de dados para o Estado da Arte do percurso metodológico planejado. Essa busca inicial se constituiu na intenção de verificar as evidências pertinentes referentes aos paradigmas metodológicos utilizados nas pesquisas nos últimos dez anos.

Os resultados apontaram que a abordagem Qualitativa tem sido parâmetro para as pesquisas em Educação em Ciências e Educação Indígena, visto o significativo percentual encontrado nos trabalhos analisados.

Ressalta-se, que o termo qualitativo em alguns trabalhos esgueira-se sobre a variação dessa abordagem nos diferentes tipos de pesquisa que utilizam técnicas e instrumentos similares.

Revista REAMEC, Cuiabá - MT, v. 5, n. 2, jul/dez 2017, ISSN: 2318-6674

Revista do Programa de Doutorado da Rede Amazônica de Educação em Ciências e Matemática http://periodicoscientificos.ufmt.br/ojs/index.php/reamec 


\section{REVISTA REAMEC}

Revista da Rede Amazônica de Educação

em Ciências e Matemática

É coeso pensar, que para os estudos com enfoques no campo da cultura cotidiana ou cultura tradicional, a partilha de saberes pode ser significante e produtivo se a abordagem estiver voltada para o paradigma qualitativo, pois, por mais que a interpretação necessite de categorias bem definidas, o conhecimento do humano pode ter maior visibilidade se estiver amparado por um enfoque que considere suas especificidades e complexidades.

Assim, os estudos refletem que a abordagem qualitativa permite a compreensão detalhada dos significados e das características situacionais dos sujeitos envolvidos, preocupa-se com uma realidade que não pode ser quantificado e nem reduzido à operacionalização de variáveis, enfatizando que a finalidade da pesquisa cientifica não está centrada tão somente na exposição de um relatório ou descrição dos dados, mas no relato do desenvolvimento interpretativo dos dados obtidos.

\section{REFERÊNCIAS}

ANDRÉ, Marli Eliza D. A. de. Etnografia da prática escolar. 7 ed. Campinas: Papirus, 2002.

ANTUNES, Fabiano. O trabalho docente em ciências como tradição pedagógica. Tese, Londrina: Programa de pós-graduação em Educação em Ciência e Educação Matemática, 2011.

BACHELARD, Gaston. A formação do Espirito Cientifico: contribuição para uma psicanálise do conhecimento. Rio de Janeiro: Contraponto,1996.

BERNAL, Roberto Jaramillo. Índios Urbanos: Processo de reconformação das Identidades Étnicas Indígenas em Manaus. Manaus: EdUFAM, 2009.

BRASIL, Constituição de 1988. Brasília: Senado Federal, 1988.

CHARTIER, Roger. A História cultural: entre práticas e representações. 2.ed. Portugal: Difel, 2002.

CHIZZOTTI, A. Pesquisa qualitativa em Ciências humanas e sociais. Petrópolis: Vozes, 2006.

Revista REAMEC, Cuiabá - MT, v. 5, n. 2, jul/dez 2017, ISSN: 2318-6674

Revista do Programa de Doutorado da Rede Amazônica de Educação em Ciências e Matemática http://periodicoscientificos.ufmt.br/ojs/index.php/reamec 
CRESWELl. J. W. Projeto de Pesquisa: Métodos Qualitativo, Quantitativo e Misto. Porto Alegre: Artmed, 2010.

DESLAURIERS, J.P e KÉRISIT, M. O delineamento de pesquisa quantitativa. In: POUPART, J., DESLAURIERS, J. P.; GROULX, L-H.; LAPERRIÈRE, A.; MAYER, R. e PIRES, A. P. A Pesquisa Qualitativa: enfoques epistemológicos e metodológicos. Petrópolis: Vozes, 2008.

FERREIRA, Gecilane. O ciclo didático e as etnociências como proposta de contextualização do ensino de ciências na educação básica. Tese, Cuiabá: Programa de Pós-Graduação em Educação em Ciências e Matemática, 2014.

FLORES, JOSÉ FRANCISCO. Integração entre cultura científica e cultura artística no ensino de ciências. Tese (doutorado), RGS: Programa de Pós-Graduação em Educação em Ciências e Matemática da Pontifícia Universidade Católica do Rio Grande do Sul, 2016.

FREIRE, P. Educação como prática da liberdade. Rio de Janeiro: Paz e Terra, 1996.

FOUREZ, Gérard. A construção das ciências: Introdução a Filosofia e à Ética das Ciências. São Paulo: Unesp, 1995.

Crise no ensino de ciências? Revista Investigação em Ensino de ciências. V. 8, p.102-123, 2003. www.capes.org.br, acesso em: 08.02.2011, as 12 h.

GEETZ, Clifford. A interpretação das culturas. Rio de Janeiro: Guanabara Koogana, 1989.

GHEDIN, Evandro; MARTINS, Lizandra Vieira. O ensino de Ciências e suas Epistemologias. Boa Vista: EDUFRR, 2017- VICO, Giambattista. A ciência Nova (1744). Tradução inédita de Marco Lucchesi. Rio de Janeiro: Record, 1999.

GIL, Antônio Carlos. Métodos e técnicas de pesquisa social. 6. Ed. São Paulo: Atlas, 2008.

LUCIANO, Gersen dos Santos. O Índio Brasileiro: o que você precisa saber sobre os povos indígenas no Brasil de hoje. Brasília: Ministério da Educação, Secretaria de Educação Continuada, Alfabetização e Diversidade/LACED/Museu Nacional, 2006.

MAHER, Machado Terezinha. A formação de professores indígenas: uma discussão introdutória. In:(org.) GRUPIONI, Luís Donisete. Formação de Professores Indígenas: Repensando Trajetórias. MEC/UNESCO Brasília, 2006.

MAIA, Dayse Peixoto. Necessidades formativas da pós-modernidade e a formação contínua de professores de ciências. Tese (Doutorado) Manaus/AM: Programa de pósgraduação em Educação em Ciências e Matemática, 2015.

Revista REAMEC, Cuiabá - MT, v. 5, n. 2, jul/dez 2017, ISSN: 2318-6674

Revista do Programa de Doutorado da Rede Amazônica de Educação em Ciências e Matemática http://periodicoscientificos.ufmt.br/ojs/index.php/reamec 
MARCONI, Marina de Andrade; LAKATOS, Eva Maria. Metodologia Científica. 6 ed. São Paulo: Atlas, 2011.

MELIÀ, Bartomeu. Educação indígena na escola. Cadernos Cedes, ano XIX, no 49, Dezembro/99.

MOREIRA, Marco Antonio. A teoria dos campos conceituais de Vergnaud, o ensino de ciências e a pesquisa nesta área. Revista Investigação em ensino de ciências. V.7, p.7-29, 2002. www.capes.org.br, acesso em: 03.02.2011, as $14 \mathrm{~h}$.

OLIVA, Alberto. À espera da ciência: um mundo de fatos pré-interpretados. Episteme, Porto Alegre, no 13, p. 17-43, jul-dez, 2001.

Teoria do conhecimento. Rio de Janeiro: J. Zahar, 2011. ( Coleção

Passo a passo).

OLIVEIRA, Elisângela Silva de. ENSINO DE CIÊNCIAS NOS ANOS ESCOLARES INICIAIS: o que professoras dizem de si e de sua docência. Tese, Belém/PA: Programa de PósGraduação em Educação em Ciências e Matemática, 2016.

PEDROSA, Eliane Maria Pinto. O ensino de ciências da natureza e de matemática em curso técnico integrado ao médio para jovens e adultos: concepções e ações da formação. Tese, Belém/PA: Programa de Pós-Graduação em Educação em Ciências e Matemática - REAMEC, 2015.

PEREIRA, Carlos Luis. O ensino de ciências naturais em uma escola indígena pataxó da Bahia. Tese (doutorado) - São Paulo: Programa de Pós-Graduação em Ensino de Ciências e Matemática, Universidade Cruzeiro do Sul, 2014.

RIBEIRO, Darcy. O povo brasileiro: a formação e o sentido do Brasil. São Paulo: Companhia das Letras, 2006.

RIBEIRO, Kátia Dias Ferreira. FORMAÇÃO DE PROFESSORES DE CIÊNCIAS NATURAIS EM UMA PERSPECTIVA INTERDISCIPLINAR E CRÍTICA: Reflexões sobre a contribuição da vivência com questões sociocientíficas na mobilização e aprendizagem de conhecimentos para a docência. Tese, Cuiabá:Pósgraduação em Educação em Ciências e Matemática (PPGECEM), 2016.

SAMPIERI, Roberto Hernández; COLLADO, Carlos Fernández; LUCIO, Pilar Baptista. Metodología de La investigacion. 4 ed. Mexico: MCGRAW-HILL Interamericana, 2006.

SANTOS, CREUSA BARBOSA DOS. Formação de Professores: Saberes Pedagógicos e Tradicionais da Etnociência para os Anos Iniciais em Escolas Quilombolas. Tese (doutorado) Belém/PÁ: Programa de pós-graduação em Educação em Ciências e Matemática, 2016

Revista REAMEC, Cuiabá - MT, v. 5, n. 2, jul/dez 2017, ISSN: 2318-6674

Revista do Programa de Doutorado da Rede Amazônica de Educação em Ciências e Matemática http://periodicoscientificos.ufmt.br/ojs/index.php/reamec 


\section{REVISTA REAMEC}

\section{Revista da Rede Amazônica de Educação em Ciências e Matemática}

SILVA, R. H. D. A autonomia como valor e articulação de possibilidades: $O$ movimento dos professores indígenas do Amazonas, de Roraima e do Acre e a construção de uma política de educação escolar indígena.Caderno Cedes, ano XIX, $\mathrm{n}^{\circ}$ 49, Dezembro/99.

SILVA, Marilene Correa da. O Paiz do Amazonas. Manaus: Valer, 2004.

TREVISAN, Inês. A aula de campo: espaço de formação inicial de professores de ciências/biologia. Tese, Belém/PA: Pós-Graduação em Educação em Ciências e Matemática da Rede Amazônica de Educação em Ciências e Matemática, 2015.

VIEIRA, EDUARDO PAIVA DE PONTES. Ser vivo, ser espécie, ser classificado: epistemes, dispositivos e subjetivações no ensino de ciências e biologia. Tese (doutorado) Belém/PÁ: Programa de pós-graduação em Educação em Ciências e Matemática, 2013.

Submetido em: 14 de outubro de 2017.

Aprovado em: 15 de novembro de 2017

Revista REAMEC, Cuiabá - MT, v. 5, n. 2, jul/dez 2017, ISSN: 2318-6674

Revista do Programa de Doutorado da Rede Amazônica de Educação em Ciências e Matemática http://periodicoscientificos.ufmt.br/ojs/index.php/reamec 